\title{
Antibiotic dry buffalo therapy: effect of intramammary administration of benzathine cloxacillin against Staphylococcus aureus mastitis in dairy water buffalo
}

\author{
Jacopo Guccione1, Luigi D'Andrea ${ }^{1 *}$ (D), Antonella Pesce ${ }^{2}$, Fausto Toni ${ }^{3}$, Giuliano Borriello ${ }^{1}$, Caterina Salzano²,
} Francesco Diuccio ${ }^{3}$, Massimo Pascale ${ }^{4}$ and Paolo Ciaramella ${ }^{1}$

\begin{abstract}
Background: Mastitis is one of the most costly diseases in Mediterranean buffalo (MB). At present, just a few specific antibiotics registered for this dairy specie have been synthetized. Efficacy of an antibiotic dry buffalo therapy (aDBT) against Staphylococcus aureus (S. aureus) mastitis, based on intra-quarter administration of $600 \mathrm{mg}$ of benzathine cloxacillin, have been evaluated for the first time. Eighty MB's quarters received a drying-off therapy (aDBT-group) and 80 were left untreated (no-aDBT-group). They were sampled at drying-off (pre-treatment) and at the resumption of milking $[<10$ days in milk (DIM)]. Fresh calver mastitis rate, dry period new mastitis rate, dry period cure rate, and persistent mastitis rate were calculated for clinical monitoring. Overall proportion of positive quarters/ animals, quarters affected by mastitis or intramammary infections (IMI), effects on somatic cell count (SCC) and milk yield were also assessed.

Results: An inter-group difference (aDBT vs. no-aDBT) was recorded for all the indexes considered. An intra-group (drying-off vs. < 10 DIM) difference was detected in aDBT-group regarding the proportion of positive-cultured quarters and animals. Concerning the latter, an inter-groups difference was also recorded at second sampling. No clinical mastitis due to the $S$. aureus was observed. Regarding the subclinical ones, a higher intra-group difference was observed in aDBT than no-aDBT group, while an inter-group difference was recorded at second sampling. No protective effect was observed against IMI. SCC showed an inter-group difference at second sampling, while none difference was instead detected for milk yield.
\end{abstract}

Conclusions: The effects against $S$. aureus mastitis of benzathine cloxacillin administration at drying-off were assessed for the first time in MB. Its use shows encouraging results in reducing the proportion of mastitis and positive animals at the resumption of the lactation.

Keywords: Antibiotic dry therapy, Mastitis, Water buffalo, Staphylococcus aureus, Benzathine cloxacillin

\footnotetext{
* Correspondence: luigi.dandrea@unina.it

'Department of Veterinary Medicine and Animal Production, University of Napoli Federico II, Via Delpino 1, 80137 Naples, Italy

Full list of author information is available at the end of the article
}

(c) The Author(s). 2020 Open Access This article is licensed under a Creative Commons Attribution 4.0 International License, which permits use, sharing, adaptation, distribution and reproduction in any medium or format, as long as you give appropriate credit to the original author(s) and the source, provide a link to the Creative Commons licence, and indicate if changes were made. The images or other third party material in this article are included in the article's Creative Commons licence, unless indicated otherwise in a credit line to the material. If material is not included in the article's Creative Commons licence and your intended use is not permitted by statutory regulation or exceeds the permitted use, you will need to obtain permission directly from the copyright holder. To view a copy of this licence, visit http://creativecommons.org/licenses/by/4.0/ The Creative Commons Public Domain Dedication waiver (http://creativecommons.org/publicdomain/zero/1.0/) applies to the data made available in this article, unless otherwise stated in a credit line to the data. 


\section{Background}

Mastitis can be considered one of the most expensive diseases for Mediterranean buffalo (MB) farmers and the resulting dairy food chain $[1,2]$. Based on what has been reported in the literature, several contagious, (e.g. Staphylococcus aureus, Streptococcus agalactiae), environmental (e.g. Streptococcus dysgalactiae, Escherichia coli) and opportunist (e.g. Coagulase-Negative Staphylococci, Streptococcus pluranimalium) bacteria were recognized as mastitis-causing in MB [3-5]. Although recent studies show a decrease of milk yield in buffalo herd affected by mastitis-causing bacteria and a consequent farm's gain reduction, information on their epidemiology within the herd, clinical findings related, and strategies for integrated problem management are still rare and incomplete compared to cow medicine [5-7]. According to our previous studies, Staphylococcus aureus (S. aureus) can be considered one of the most representative gram-positive bacteria causing in-udder disorders and alterations of mammary secretion in MB. Indeed, $S$. aureus has been associated with a high dry period new infection rate within the herd (up to 55.5\%), a significant increase of SCC values, a decrease of milk yields, quality, and farm's economic incomes when it causes subclinical (SCM) and clinical mastitis (CM) $[2,5,6,8]$.

In $\mathrm{MB}$ as described in cow, a beginning of lactation with a low prevalence of intramammary infection (IMI) is a desirable prerequisite to ensure optimal milk productions and udder health during the following milking time [7, 9, 10]. During the dry period, the goal of udder-health management programs is to minimize the number of infected quarters at calving and the chances of increases of SCC in early lactation stages $[9,10]$. Both in MB and cow's lactation stages, this is recognized as a critical time for mastitis control $[4,9,10]$, nevertheless only for the second one, several strategies have been developed to control the effects of mastitis-causing bacteria. In this respect, antimicrobial dry therapy represented a cornerstone of any mastitis control program over the years. As reported in the literature, in-teats infusions of slowrelease antibiotic preparations should cure the existing IMIs and protect the cows by new infections that could originate from this period [11]. As the prevalence of persistent contagious pathogens declined over-time, the need for a blanket dry cow therapy consequently decreased [11, 12]. The change has been also promoted by several controversies concerning the complex, and sometimes unclear, cause and effect relationship existing between this type of therapy and the appearance of antibiotic-resistant microorganisms [11, 12]. As a result, the attention has been focused on different strategies such as the selective dry cow therapy: a pathogen-, cow- and herd-specific treatment method [7, 12, 13]. Nevertheless, even the latter cannot be considered as a universal remedy because herd characteristics and management can deeply limit its use at an individual-cow level [11].
Unfortunately, MB's medicine suffers from poor scientific knowledge compared to the bovine one, regarding this relevant topic [5], and at the best of the authors' knowledge, no studies investigated the antibiotic's clinical efficacy in $\mathrm{MB}$ at drying-off, so far. Even though some MB's farms perform antibiotic dry buffalo therapy $(\mathrm{aDBT})$, there is no evidence proving the effectiveness of this strategy for bacteria control in these ruminants characterized by a dry-off period even longer than cows ( $\sim 4$ months) [5]. Although on one side aDBT protocols are performed by veterinary practitioners merely transferring knowledge arising from bovine medicine, on the other one the issue becomes even more serious considering that just a few antibiotics are specifically synthesized for MB [13]. The legal inclusion of buffalo within the bovine species by the EU since 2009 [14], promoted the use of drugs manufactured for bovine in these ruminants, without scientific proves of their efficacy [13]. For this reason, a sensible reduction of emphasis on the responsible use of antibiotics has been observed as the main effect.

Based on the previous considerations, the present manuscript aims to investigate for the first time the clinical outcomes originating from a dry buffalo therapy against S. aureus mastitis. Therefore, the effects of an intramammary administration of benzathine cloxacillin have been defined through (i) the calculation of clinical indexes for mastitis monitoring, (ii) the assessment of the effects on udder health and (iii) milk yield.

\section{Results}

\section{Farm and animals}

Out of eight farms investigated, the selected one was the only meeting the eligibility criterion. In this farm, no differences in all the aspects of herd management practices were observed during the two study years (e.g. therapeutic protocols for mastitis, milking routine, feeding and housing system, dairy workers, etc.).

Regarding the overall number of $\mathrm{MBs}$ investigated, it represents the result of restrictive eligible criteria used, noticeably reducing the freedom of animal selection. Moreover, the enrolment originated from all MBs driedoff during the first useful season after farm detection (summertime), and thereby prolonging beyond that period the recruitment would have been achieved a sampling population even more over-time distributed and without the possibility to reduce possible seasonal influences on the results (e.g. different environmental conditions).

None MB (both in aDBT and no-aDBT group) shows neither signs of milk leaking in the first week or swollen quarters and teat damage during the entire dry period.

\section{Bacteriological milk culture}

During the investigation, 640 quarters milk samples have been collected and submitted to SCC analysis and BMC 
(i.e. $40 \mathrm{MBs} \times 4$ quarters sampled 2 times $\times 2$ samplings time). A full agreement was always found for $S$. aureus identification when double samples have been cultured.

Type and proportion of the in-udder pathogens isolated at the two samplings times and in both the groups are reported in detail in Table 1. Briefly, $S$. aureus was the most commonly isolated in both the samplings and groups, followed by coagulase-negative staphylococci (CNS) at drying-off, and E. coli at first sampling of the new lactation. The overall percentage of other udder pathogens detected (not-S. aureus) was $19.8 \%(16 / 80)$ in aDBT group and $22.4 \%(18 / 80)$ in noaDBT one at drying-off, while it was $52.3 \%(42 / 80)$ and $58.4 \%(47 / 80)$ in the same groups within 10 DIM, respectively. Negative-culture status was observed in $41.2 \%(33 / 80)$ and $11.2 \%(9 / 80)$ of the samples in aDBT and no-aDBT groups at drying-off, respectively; the $13.7 \%(11 / 80)$ and $27.5 \%(22 / 80)$ were instead recorded in the same groups within 10 DIM.

\section{Clinical indexes for mastitis monitoring}

Concerning the fresh calver mastitis rate, a significant difference $(P<0.001)$ was recorded between the proportions detected in the aDBT $(1.3 \%, 1 / 80)$ and in the noaDBT groups $(20.0 \%, 16 / 80)$. An additional inter-group difference $(P<0.01)$ was observed regarding the $d r y$ period new mastitis rate due to $S$. aureus. Indeed, no new cases were observed in the treated group (0/13), while they were found in the untreated one with a proportion of $44.4 \%$ (8/18). Regarding the dry period cure rate and persistent mastitis rate caused by $S$. aureus, a significant inter-group difference was recorded for the first $(P<0.0001)$ and the second $(P<0.05)$ parameter mentioned. Indeed, a proportion of cured quarters of 97.4\% (37/38) and 41.7\% (10/24) was found in aDBT and no-aDBT group, respectively; for the second index, the proportion of not-cured quarters was instead of $2.6 \%$ $(1 / 38)$ in aDBT group and $20.8 \%(5 / 24)$ in the no-aDBT.

\section{Udder health status}

The overall proportion of $S$. aureus positive-cultured quarters at drying-off was $50.0 \%(40 / 80)$ in aDBT group and $41.2 \%(33 / 80)$ no-aDBT one; the same parameter evaluated within 10 DIM showed a proportion of $22.5 \%$ $(18 / 80)$ and $36.3 \%$ (29/80), respectively. A statistically significant intra-group difference has been observed in the treated group $(P<0.01)$, while an inter-group difference was found for the sampling within 10 DIM $(P<0.01)$.

The proportion of quarters affected by $S$. aureus infection with different health status are laid down in detail in Table 2. Briefly, neither in aDBT or no-aDBT group CM due to the $S$. aureus were never observed during the entire investigation. Regarding SCM, a statistically significant intra-group difference has been observed between the two samplings time both in the treated $(P<0.01)$ and untreated group $(P<0.05)$; an inter-group difference has been also detected at milk resuming $(P<0.001)$ (Table 2$)$. The RR of mastitis calculated within 10 DIM in aDBT group (1/79) than no-aDBT group (16/64) was 0.06 (95\% $\mathrm{CI}=0.01-0.46 ; P<0.01)$. In all the quarters affected by SCM, S. aureus was always isolated in mono-infection.

Regarding IMI, a statistically significant intra-group difference has been observed only in the treated group $(P<0.001)$ (Table 2). At drying-off, $S$. aureus has been always detected in co-infection in quarters affected by IMI. Furthermore, at the first sampling of the new lactation, it was instead detected as responsible of coinfection in $58.8 \%$ of cases $(10 / 17)$ in a-DBT group, and in $61.5 \%(8 / 13)$ in no-aDBT group. All co-infections were always caused by not-recognized udder specific pathogens in buffalo (i.e. Lactobacillus $7 / 28$, Geobacillus toebii 5/28, Kocuria rosea 8/28, Kocuria kristinae 8/28).

Instead, the overall proportion of udders of buffaloes positive for $S$. aureus at drying-off was $75.0 \%(15 / 20)$ and $65.0 \%(13 / 20)$ in aDBT and no-aDBT group, respectively. The same parameter evaluated at the first sampling of the new lactation gave a proportion of $40.0 \%(8 / 20)$ and $65.0 \%(13 / 20)$, respectively. A statistically significant intra-group difference has been observed only in the treated group $(P<0.001)$. Regarding the aDBT group, the $65 \%$ of the animals $(13 / 20)$ showed at least one quarter with SCM at dry-off (i.e. $1 \mathrm{MB}$ with 1 quarter affected by SCM, 3 MBs with 2 quarters, 5 MBs with 3 , and $4 \mathrm{MBs}$ with 4 ). In this group, the only case of SCM recorded at milking resumption belonged to one subject that cured 3 of the 4 quarters affected.

\section{SCC and milk yield}

Data regarding Log10 SSC and milk yield recorded in both the samplings, either for aDBT or for no-aDBT, are reported in detail in Table 3. Briefly, regarding the overall average of SSC, no significant, differences were observed between the two groups at drying-off, while it was found at second sampling (aDBT vs. no-aDBT, $P<0.01$ ). Moreover, intra-group differences have been detected within both within the aDBT group $(P<0.0001)$ and the noaDBT one $(P<0.001)$. If quarters affected by mastitis due to $S$. aureus are discharged from the analysis, an intergroup significant difference is observed only in the first sampling in the new lactation $(P<0.05)$; an intra-group difference was detected only for aDBT animals $(P<0.05)$.

Finally, regarding the daily mean milk yield, no significant inter-group differences were observed in both the samplings. Intra-group differences were instead found both within the aDBT group $(P<0.0001)$ and within the no-aDBT one $(P<0.0001)$. If quarters affected by mastitis are discharged from the analysis, no significant 


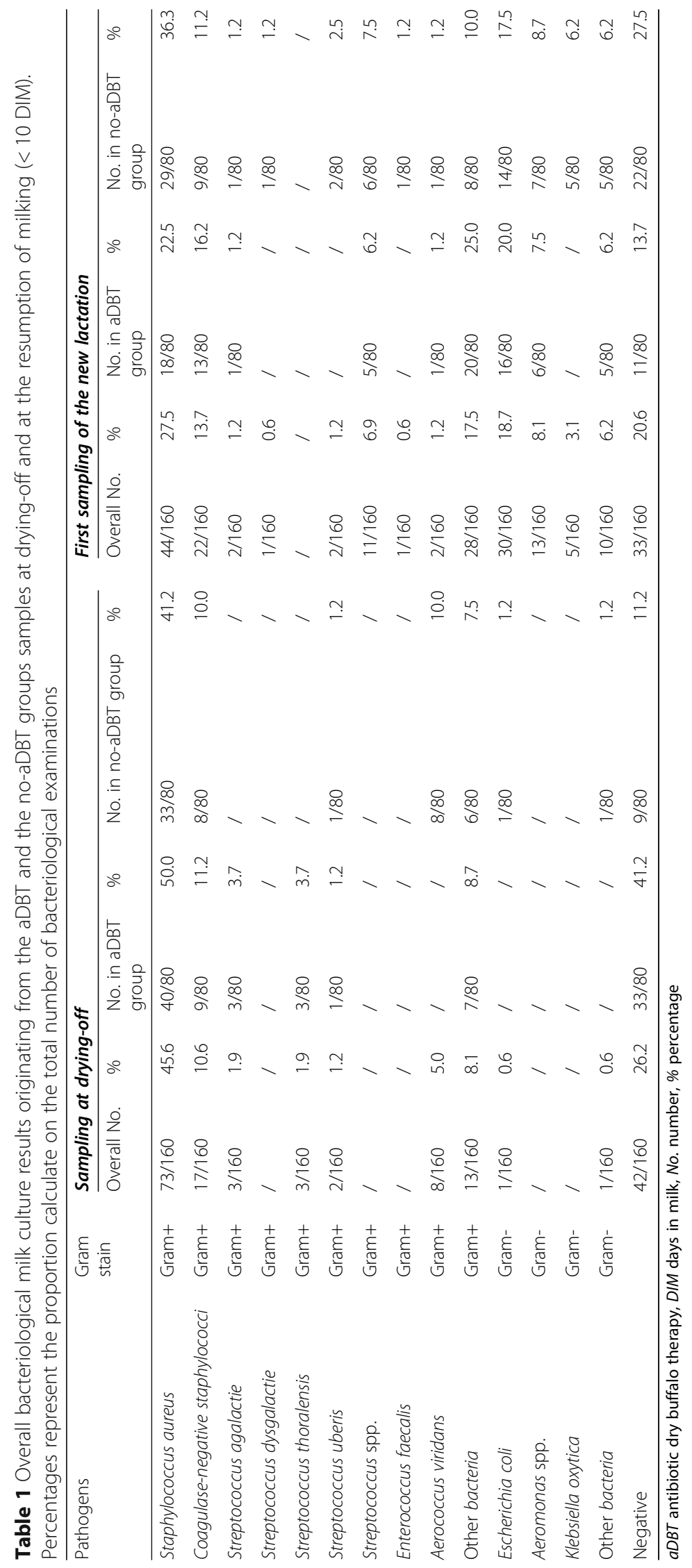


Table 2 Different quarters' health status in pluriparous Mediterranean buffalos affected by S. aureus infections in aDBT and no-aDBT groups. Samplings were performed at drying-off and at the resumption of milking (<10 DIM). Percentages represent the proportion calculate on the total number of quarters enrolled

\begin{tabular}{|c|c|c|c|c|c|c|c|c|}
\hline \multirow{2}{*}{$\begin{array}{l}\text { Clinical } \\
\text { status }\end{array}$} & \multicolumn{4}{|c|}{ Sampling at drying-off } & \multicolumn{4}{|c|}{ First sampling of the new lactation } \\
\hline & $\begin{array}{l}\text { No. in aDBT } \\
\text { group }\end{array}$ & $\%$ & $\begin{array}{l}\text { No. in no- aDBT } \\
\text { group }\end{array}$ & $\%$ & $\begin{array}{l}\text { No. in aDBT } \\
\text { group }\end{array}$ & $\%$ & $\begin{array}{l}\text { No. in no-aDBT } \\
\text { group }\end{array}$ & $\%$ \\
\hline CM & l & l & / & / & / & l & / & / \\
\hline SCM & $38 / 80^{c}$ & 47.5 & $25 / 80^{\mathrm{a}}$ & 31.2 & $1 / 80^{d, e}$ & 1.3 & $16 / 80$ & $20.0^{b, f}$ \\
\hline $\mid \mathrm{Ml}$ & $2 / 80^{e}$ & 2.5 & $8 / 80$ & 10.0 & $17 / 80^{f}$ & 21.3 & $13 / 80$ & 16.2 \\
\hline
\end{tabular}

$\overline{a D B T}$ antibiotic dry buffalo therapy, DIM days in milk, No. number, $a D B T$ antibiotic dry buffalo therapy, \% percentage, $C M$ clinical mastitis, SCM subclinical mastitis, IMI intramammary infection; ${ }^{\mathrm{a}, \mathrm{b}} P<0.05 ;{ }^{\mathrm{c}, \mathrm{d}} P<0.01$; $^{\text {e,f }} P<0.001$

inter-group differences are assessed; they can be instead found both for the aDBT group $(P<0.0001)$ and for the no-aDBT one $(P<0.0001)$.

\section{Discussion}

Estimation under field conditions of aDBT effects against $S$. aureus mastitis with supposed dry period origin is an interesting challenge in a dairy species like MB where the knowledge regarding management of mastitis are almost rare [1]. The complete lack of previous knowledge concerning the effect of an aDBT forced the authors to careful and methodical approach for the evaluation of the outcomes resulting from an antibiotic synthesized for dairy cows in origin. Therefore, the intended goal has been achieved verifying the tolerance of the animals to the product, detecting udder's clinical findings, recording the milk quality and yields, as performed in other previous studies $[5,10]$.

The responsible use of antibiotics and the concerns regarding potentially resulting bacterial resistance, affect both veterinary and human medicine [15]. Therapy at dry-off is one of the most important herd management areas where the previous concepts should be applied, representing a true challenge for the next future. Only

Table 3 Overall averages of somatic cells count and milk yields as well as data relative to negative and IMI buffaloes belonging to aDBT and no-aDBT groups at the two samplings time (dry-off and $<10$ DIM)

\begin{tabular}{|c|c|c|c|c|}
\hline \multirow[t]{2}{*}{ Samplings } & \multicolumn{2}{|l|}{ aDBT } & \multicolumn{2}{|l|}{ no-aDBT } \\
\hline & Overall & Neg. and IMI & Overall & Neg. and IMI \\
\hline \multicolumn{5}{|c|}{ SCC ( $\log _{10}$ cells $\left./ \mathrm{mL}\right)$} \\
\hline Drying-off & $5.7 \pm 1.1^{\mathrm{g}}$ & $5.2 \pm 0.8^{\mathrm{A}}$ & $5.8 \pm 0.7^{e}$ & $5.5 \pm 0.7$ \\
\hline$<10$ DIM & $5.0 \pm 0.7^{c, h}$ & $4.9 \pm 0.6^{\mathrm{a}, \mathrm{B}}$ & $5.4 \pm 0.6^{d, f}$ & $5.2 \pm 0.6^{b}$ \\
\hline \multicolumn{5}{|c|}{ Milk yield (L/d) } \\
\hline Drying-off & $0.4 \pm 0.2^{a}$ & $0.4 \pm 0.1^{a}$ & $0.5 \pm 0.2^{a}$ & $0.5 \pm 0.2^{a}$ \\
\hline$<10$ DIM & $5.3 \pm 1.5^{\beta}$ & $5.2 \pm 1.4^{\beta}$ & $5.2 \pm 1.1^{\beta}$ & $5.3 \pm 1.1^{\beta}$ \\
\hline
\end{tabular}

aDBT antibiotic dry buffalo therapy, SCC somatic cell count, Log logarithm, $\mathrm{mL}$ millilitres, Neg. negative, $I M I$ intramammary infection, DIM days in milk, $L$ litres, $d$ days. Statistical significances for $\mathrm{SCC}$ are reported as: ${ }^{\mathrm{a}, \mathrm{b}} P<0.05,{ }^{\mathrm{A}, \mathrm{B}} P<0.05$, c,d $P<0.01 ;{ }^{\text {e,f }} \mathrm{P}<0.001 ;{ }^{\text {g,h }} P<0.0001$. Statistical significances for milk yields have to be considered within the columns: ${ }^{a, \beta} P<0.0001$ the uphold of principles such us responsible use of antibiotics, analysis of past prescribing practices and outcome, combined with robust clinical research evidence can represent a starting point for rational and efficient use of antibiotics in $\mathrm{MB}$ as much as in cows $[15,16]$. To interpret these principles, the present study provides evidence on clinical findings associated with aDBT allowing some scientific considerations never conceived of before in MB's mastitis management. Our investigation may be considered a starting point to build the essential basic knowledge, to understand the importance of antibiotics rational use even in this specie, to promote further studies investigating the effects on udder health of selective/targeted treatments. As described in cow medicine $[15,16]$, the approach to aDBT cannot be only focused on antibiotic use but should be supported by a complete knowledge of factors: social environment (e.g. attitude to antibiotic use), pharmacological environment (e.g. available products), and physical environment (e.g. spaces for the animals, management). According to the authors' opinion, the lack of relevant knowledge may represent a strong point since the scientific community may look to bovine medicine as an example, avoiding to make analogous mistakes and taking only the best experiences and conclusions. Indeed, in the last years, the continuous transferring of knowledge from bovine herd management practices to $\mathrm{MB}$ is enabling the appearance of analogous pathologies [1, 17] and herd problems [18], emphasizing the necessity to improve knowledge regarding animal health and farm profitability $[2,19,20]$.

According to the label's indications [21], the bactericidal in action and not destroyed by staphylococcal betalactamase antibiotic used during the study was characterized by an off-white stable suspension of cloxacillin as the benzathine salt in a long-acting mineral oil base, prepared under sterile conditions. Its use in dairy cow has been recommended for routine use at drying-off, to treat existing IMI and to provide prolonged protection against new infections during the dry period [21]. Orbenin Extra is described as active against Gram-positive mastitis-causing bacteria including Trueperella pyogenes, streptococci (e.g. Str. agalactiae, Str. dysgalactiae, Str. uberis), penicillin- 
resistant and sensitive staphylococci (e.g. S. aureus). The present investigation has been focused on clinical outcomes originating from an aDBT against $S$. aureus. Indeed, in our previous studies, this microorganism has been detected as the most representative Gram-positive in-udder pathogens, related with high contagiousness, causing mastitis and economic losses due to its negative influence on milk quality and yield in dairy $\operatorname{MB}[2,5,6]$. Considering the overall $\mathrm{BMC}$, a high-frequency isolation of $S$. aureus followed by CNS has been recorded in both the groups (Table 1). Analogous behaviour has been described both in MB [6] and cow herds [22], where frequencies of isolation of CNS and Streptococci were indeed considerably lower in herds positive for S. aureus. Moreover, as reported also cows [23], an evidence of its high contagiousness and pathogenicity can be also considered the high mono-infection isolation frequency observed both in treated and untreated groups during both the samplings.

The main goal of the present study was to verify the effects on S. aureus mastitis with likely dry period origin by means of calculation of clinical indexes. Nevertheless, to avoid a potential bias related to a fix classification of udder health status on the results, the authors during analysis evaluated before the overall proportion of animals/quarters infected independently from their udder health status. The observed results regarding (i) a significant decrease of positive buffaloes and quarters in aDBT group (drying-off vs. $<10$ DIM; $P<0.05$ and $P<0.01$, respectively), (ii) the inter-group difference for the same parameter at milking resumption (aDBT vs. no-aDBT, $P<0.01$ ), and (iii) the overall reduction of monoinfection cultured within the aDBT group (drying-off vs. $<10$ DIM, $P<0.0001)$ may provide a first interesting indication of benzathine cloxacillin's effects in reducing and managing $S$. aureus udder's infections, as described also for cows [24].

The end of lactation is a common time to administer antimicrobial therapy to $S$. aureus infected dairy cow because antibiotics can remain in the udder at higher concentrations for prolonged periods to effect a cure [25]. As described by Reeve-Johnson and Nickerson (2017), this microorganism is one of the most difficult to treat, especially during lactation, and there are no intramammary infusion products currently available that effectively eliminate $S$. aureus IMI from herds. During the present study, a reduction of SCM has been recorded in the second sampling compared to the first one in both the groups, although the difference was greater within the treated group than within the untreated one $(P<$ 0.01 in the aDBT group vs. $P<0.05$ in the no-aDBT group). Indeed, the survey showed encouraging results regarding the efficacy of the aDBT against SCM due to $S$. aureus. The results is confirmed by the very low RR value indicating a decreased risk of mastitis in $\mathrm{MBs}$ exposed to the antibiotic ( $R R=0.06, P<0.01)$, and by the clinical indexes showing higher dry period cure rate (aDBT group vs. no-aDBT group, $P<0.0001$ ), lower persistent mastitis rate (aDBT group vs. no-aDBT group, $P<0.05)$ and dry period new mastitis rate (aDBT group vs. no-aDBT group, $P<0.01$ ), in treated group than control one. Despite the potential beneficial effects observed, an assessment of the limitations may be represented by the chosen study design: indeed, the evaluation of the direct aDBT effects (without the attempt to estimate the overall population estimates), as well as the lack of information regarding the effect over-time may potentially produce an overestimation of the results observed. For these reasons, a further purpose is going to assess the effectiveness of aDBT on an entire MBs' herd through a longitudinal study estimating the clinical outcomes entailed.

The non-lactating period can be considered a strategic moment for udder health because dry animals can recover from IMI present at drying-off [25]. Nevertheless, udder health can also be threatened as many cows acquire new IMI during the dry period [25]. This phenomenon may be considered the reason for the lack of efficacy against the appearance of new IMI due to S. aureus during dry-off. Regarding this point, the comparison with the results originating from cow medicine would be very difficult, since previous research on this topic aimed only to verified the effects of benzathine cloxacillin in animals with SCC > $200 \times 103$ cells $/ \mathrm{mL}$, and do not investigate the ability to prevent intramammary infection (i.e. infections do not producing a rise of SCC values above the threshold of normality) $[5,6]$. In general, as reported for dairy species treated at dry-off [25-30], the effectiveness of a therapeutic protocol may be influenced several variables such as herd characteristics and management (e.g. prevalence of infected animals, lack of mastitis monitoring, etc.), length of dry-off (e.g. increased exposure to risk factors, etc.), biosecurity actions (e.g. farm's hygiene protocols, etc.), type of treatment (e.g. administration route, posology, etc.) and lactation period (e.g. timing for sampling, etc.), that alone or interacting between them, can significantly influence the results observed.

According to the authors' opinion, although aDBT showed an ability to mitigate the proportion of in-udder mono-infection due to $S$. aureus, two main factors may have adversely affected this parameter considered: strategies of herd management used during dry-off and length of this period. Indeed, the 16 weeks characterizing MBs' dry-off period may increase the exposure time to risk factors of udder infections, regardless of whether they are treated or not [29]. Moreover, according to the label indications [21], this antibiotic should provide at least 7 weeks of protection against new infections after 
infusion, but its effectiveness during such a long dry-off period has been never studied, so far. Based on the previous considerations, the use of benzathine cloxacillin associated with excellent farm management practices may successfully improve the infection control within the herd at dry-off; therefore, further and more complete studies associated with suitable changes in management practices should be performed to verify the accuracy of the hypothesis.

As last, regarding the effects of aDBT on milk yield and quality, no significant inter-group difference was observed about daily mean production, while inter-and intra-group differences were detected for SCC. Regarding milk yield, it is widely described in literature that $S$. aureus can produce toxins destroying cell membranes and directly damaging milk-producing tissue in dairy cows [31, 32]. Indeed, during the infection, destruction of alveolar and ductal cells leads to the formation of scar tissue significantly limiting animals' production potential [31, 32]. Likewise, MB affected by SCM at-dry-off may have developed structural damage of the secretive tissues negatively influencing the milk production at milk resuming and explaining the results observed. Instead, concerning the difference for SCC, the administration of aDBT may have reduced the severity pathological processes in progress generating the differences observed (Table 3). Moreover, as reported in Table 2, the significant reduction of SCM and a profitable fresh calver mastitis rate associated with a significant increase of negative quarters may also take part in the significant difference observed on overall SCC mean values. A further study purpose may be represented by the concomitant use of a teat sealant in pluriparous MB at drying-off to provide additional protection against the ingress of in-udder pathogens, contributing to prevent infections and mastitis during early lactation, as well as potentially reducing antibiotics use in these dairy ruminants.

\section{Conclusions}

The clinical findings of the present investigation demonstrated for the first time the direct effects against $S$. aureus udder infection of antibiotic dry buffalo therapy based on benzathine cloxacillin. Even though a poor protective effect against new infection has been detected, likely due to a long dry-off period increasing the exposure time to risk factors for udder infections, the use of this antibiotic at drying-off seems to show encouraging results in reducing the proportion of positive MBs positive for S. aureus, the proportion of SCM due to the same pathogen, and the SCC values at the resumption of milking. Although this study was performed on a small number of animals, this investigation may be considered the starting point to build the essential basic knowledge promoting the increase of awareness necessary to understand the relevance of rational antibiotic uses in MB. The effects on the entire dairy herd under field conditions, as well as the in-depth analysis of the infectious dynamics, warrant further scientific exploration with the goal both to fully understand the effectiveness of benzathine cloxacillin in water buffalo and to create mastitis management programs ad-hoc developed for these dairy ruminants.

\section{Methods}

The entire study was performed over two consecutive years. During the first one, the farm positive for $S$. aureus has been selected while during the second one the efficacy of the selected drug has been verified.

\section{Farm selection and management}

The chosen farm was selected from a group of eight, located in Caserta district (Southern Italy), served by the local veterinary practitioner and monthly tested for bulk milk somatic cell count (BMSCC) and bacterial DNA by means of PCR-based assay as described in our previous study [5], between September 2016 and May 2017 (9months). The eligibility criterion to select the farm of the study were represented by (i) presence of $S$. aureus within the milking herd, (ii) at least, the last 3, consecutive, bulk milk samplings positive for S. aureus. No strict criteria were instead applied for BMSCC or mastitis incidence. In the deseasonalized chosen farm of 400 dairy MBs, changes in herd management practices observed during the entire period of investigation (first and second year) were recorded to exclude possible influences on the following treatment protocol.

The selected farm was characterized by herringbone parlour and animals were milked twice a day. A 9months average of $242 \pm 27$-day in milk (DIM), milk yield per head of $2420 \mathrm{~kg}$ and of BMSCC values of $256 \times$ $10^{3} \pm 37 \times 10^{3} \mathrm{cell} / \mathrm{mL}$ has been recorded. Over the same period, the mean proportions of MBs infected (\% herd currently infected, SCC > $200 \times 10^{3} \mathrm{cell} / \mathrm{mL}$ ) and chronically infected (\% MB persistently infected, SCC $>200 \times$ $10^{3} \mathrm{cell} / \mathrm{mL}$ for two of the previous three consecutive tests) were $39.8 \% \pm 6.8( \pm \mathrm{SD})$ and $22.2 \% \pm 4.6$, respectively. Regarding dried-off MBs, all of them were kept in a common paddock of $\sim 600 \mathrm{~m}^{2}(\sim 15 \mathrm{~m} \times 40 \mathrm{~m})$. The barn was characterized by a roofed common bedded, exercise areas and feeding alley, all of them characterized by solid non-grooved concrete floor (cleaned once a day). As a common practice in MB herd management, animals were abruptly dried off when they were producing $<0.5 \mathrm{~L} /$ day [5]. Dry animals were fed with a total mixed ration including hay, silage, and a multi-vitamin integrator two times a day; free access to the protected water trough was always guaranteed. 


\section{Animal enrolment and therapy}

During the second year of study, 40 of 108 (37.0\%) pluriparous MBs ( $\geq 2$ lactations), has been selected by means convenient sampling. These represent all pluriparous having the following characteristics: dried-off between June and September 2018, in good health, having 4 functional quarters, teats free of significant lesions and without obvious clinical signs of mastitis recorded during at least the last 3 months before dry-off.

The sample population selected has been randomly divided into aDBT group (made of $20 \mathrm{MBs}$ receiving therapy at drying-off) and no-aDBT group (made of 20 MBs left untreated) consisting of 80 quarters each one (overall 160 quarters). At drying-off, all the animals enrolled were individually submitted to a complete clinical examination with particular focus on the teat and udder health status [10] and received the first quarter milk sampling. At this time, the aDBT group received an intramammary administration for each quarter of 600 $\mathrm{mg}$ of benzathine cloxacillin in $3.6 \mathrm{~g}$ of suspension (Orbenin Extra ${ }^{\circ}$, Zoetis, Inc.), while the no-aDBT group was left untreated. Antibiotic dry therapy was performed according to Skidmore et al. [33]. Briefly: (i) milking the buffalo completely, utilizing proper milking technique; (ii) cleaning teats with a clean and dry towel; (iii) predipping all 4 teats with effective teat disinfectant; (iv) leaving the animal alone 5-10 min; (v) pre-dipping again; (vi) infuse antibiotics by introducing the tip only $5 \mathrm{~mm}$ into the teat canal; (vii) post-dipping all teats and keep the buffalo restrained for another hour to facilitate the closing of the teat opening and prevent the introduction of bacteria into the exposed teat opening. Moreover, all MB were daily monitored for milk leakage, during the first week after drying-off and in the last week before the estimated day of calving. One every second week, animals were also monitored for swollen quarters and teat damage during the entire dry period.

As suggested by Bradley et al. [26], to gain an insight into the likely origin of mastitis and the importance of treatment in mastitis epidemiology the second quarter milk sampling has been performed on all MBs (aDBT and no-aDBT groups) within 10 DIM of new lactation (range: 7-10 DIM, median: 9.0 DIM).

All quarters milk samples were aseptically collected as described by the National Mastitis Council [34] for dairy cows. Milk collection has been performed immediately before regular evening milking, in double aliquots and using sterile test tubes (BD Vacutainer, Oxford, UK). For all of them, bacteriological milk culture (BMC) and SCC investigations were performed to provide information about $S$. aureus presence and severity of the disorder; finally, daily milk yields were also recorded during the same samplings time using automatic dedicated software (Afifarm, Afimilk, Kibbutz Afikim, Israel).
All the milk samplings were performed during the mastitis monitoring program regularly practiced by the local veterinary practitioner (e.g. including regular SCC monitoring, data analysis, antibiotic susceptibility testing before treatments, etc.). All $\mathrm{MB}$ belonging to aDBT groups were infected by $S$. aureus susceptible to benzathine cloxacillin and other antibiotics belonging to penicillin group (i.e. ampicillin, oxacillin, penicillin G). All actions performed by the investigators abide by the common good clinical practices [35]. Moreover, the farmer was previously informed and in agreement with purposes as well as methods used.

\section{Cytological and bacteriological examination}

The examinations were performed according to the diagnostic procedures used in our previous studies $[1,4$, 6]. Briefly, milk samples were placed in a cool box $\left(4{ }^{\circ} \mathrm{C}\right)$ and brought to the reference laboratory within $1 \mathrm{~h}(\mathrm{~h})$ of collection. Samples were submitted to SCC analysis (Fossomatic 5000, Foss Electric, Hillerod, Denmark, approved for buffalo) and BMC within $2 \mathrm{~h}$ from collection. The $\mathrm{BMC}$ and bacteriological identification were performed according to the National Mastitis Council guidelines [36]. All of them were performed without previous information about the udder's clinical status and in double (to confirm BMC results and to assign the correct bacteriological positivity). Briefly, $10 \mu \mathrm{L}$ of each milk sample was streaked on one-quarter of a bloodagar plate (Merck KGaA, Darmstadt, Germany), incubated at $37^{\circ} \mathrm{C}$ for up to $48 \mathrm{~h}$ and examined two times (at 24 and $48 \mathrm{~h}$ of incubation). Bacterial colonies were tentatively identified on gross morphology. The number and types of colonies were also recorded. As described in previous studies $[4,6,10]$, when 3 or more dissimilar colony types were isolated on the plate, the sample was considered contaminated. Gram staining and catalase testing were performed to differentiate between streptococci and staphylococci, and tube coagulase testing using rabbit plasma to differentiate between coagulase-positive and coagulase-negative staphylococci. A final identification of microorganisms was performed using the colorimetric and automatic identification system (Vitek 2 XL 120; bioMerieux Inc., Hazelwood, MO). Enterobacteriaceae have been grown on MacConkey agar (Oxoid, Basingstoke, UK) and identified using the same automatic system. Mastitogens bacteria with confidence levels greater than 0.90 were considered identified at the species level; otherwise, they were identified at the genus level. One CFU/mL was the cut-off to assign the positivity for S. aureus.

\section{Clinical definition of udder health status}

As reported in our previous studies [5, 6], different udder health status has been classified according to SCC values, microbiological status and clinical signs of 
disease. Briefly, quarters producing milk with $\mathrm{SCC}>$ $200 \times 10^{3}$ cells $/ \mathrm{mL}$ and positive BMC have been classified as affected by mastitis, with (clinical mastitis, CM) or without clinical signs (subclinical mastitis, SCM). Quarters producing milk with $\mathrm{SCC}<200 \times 10^{3}$ cells $/ \mathrm{mL}$ but positive $\mathrm{BMC}$ caused by udder specific-pathogens (i.e. belonging to the contagious, environmental or opportunistic categories) have been instead classified as affected by IMI. Finally, quarters with $\mathrm{SCC}<200 \times 10^{3}$ cells $/ \mathrm{mL}$ and negative BMC were defined as negative.

\section{Statistical analysis}

For the present investigation, only data originating from quarters considered as affected by CM, SCM and IMI due to $S$. aureus were analyzed and discussed.

Different quarter's health status, SCC, and milk yields were analyzed by standard descriptive statistics, while normality has been assessed by means of Shapiro Wilk tests, normal probability plots, and histograms was assessed. Data were expressed as absolute numbers, percentages, or mean \pm SD. Log-transformation was applied to variable not normally distributed.

As reported by Bradley et al. [26], several clinical indexes were calculated to verify antibiotic's clinical efficacy against $S$. aureus mastitis, comparing intra-group (drying-off vs. <10 DIM) and inter-group differences (aDBT vs. no-aDBT, at both the samplings). They included: (i) fresh calver mastitis rate (as the overall proportion of quarters affected by CM or SCM due to $S$. aureus within $10 \mathrm{DIM}$ ); (ii) dry period new mastitis rate (proportion of quarters affected by IMI due to S. aureus at dry-off, but developing CM or SCM within 10 DIM); (iii) dry period cure rate (proportion of quarters affected by CM or SCM due to $S$. aureus at dry-off that become affected by IMI or negative within 10 DIM); (iv) persistent mastitis rate (proportion of quarters affected by $\mathrm{CM}$ or SCM due to S. aureus at dry-off and still sick within 10 DIM). Proportion of quarters with CM, SCM, and IMI due to $S$. aureus at drying-off and milking resumption were also calculated. Instead, the proportion of animal infected was assessed considering all MBs with at least one positive quarter for $S$. aureus (i.e. affected by $\mathrm{CM}, \mathrm{SCM}$ or IMI). For each MB belonging to the aDBT group, the number of quarters affected by mastitis has been also calculated pre- and post-treatment to assess the therapy effectiveness depending on the number of quarters affected per animal. Log-transformed (SCC) and untransformed (milk yields) continuous variables were compared using simple Student's $t$-test. Significant differences between expected and observed frequencies of categorical data (e.g. clinical indexes for aDBT monitoring) were assessed using $X^{2}$-test's contingency tables. Fisher's exact test was performed in case of low expected frequencies $(<5)$. Moreover, the ratio of the probability that mastitis (CM and SCM) might occur in aDBT group (exposed group) at the resumption of milking, versus the probability that it might appear in no-aDBT (non-exposed group) has been quantified by means of Relative Risk (RR) and 95\% confidence intervals calculated according to Petrie and Watson [37].

Probabilities $<0.05$ were considered statistically significant. All the statistical data were analyzed using dedicated software (SPSS, Version 17.0, Chicago, IL, USA).

\section{Abbreviations}

aDBT: antibiotic dry buffalo therapy; BMC: Bacteriological milk culture; BMSCC: Milk somatic cell count; Cl: Confidence interval; CM: Clinical mastitis; CNS: Coagulase negative staphylococci; DIM: Days in milk; IMI: Intramammary infections; MBs: Mediterranean buffaloes; no-aDBT: No antibiotic dry buffalo therapy; SCC: Somatic cell count; S. aureus: Staphylococcus aureus; SD: Standard deviation; SCM: Subclinical mastitis; RR: Relative risk

\section{Acknowledgments}

The Authors acknowledge the precious collaboration of farmer during the study.

\section{Authors' contributions}

$J G, A P, F T, F D \& P C$ participated in the conceptual aspect and design of the study. JG, LDA, MP, GB \& PC involved in samples and data collection. JG, AP \& CS performed the samples analysis. JG, LDA, GB \& PC statistical evaluation and data interpretation. All authors provided consultation and coordination. $J G, L D A \& P C$ wrote the first draft of the manuscript, with all authors involved in reviewing. All authors read and approved the final version of the manuscript.

\section{Funding}

Zoetis, Italia s.r.l., that financially supported the study. The funding company participated in the conceptual aspect and design of the study and reviewing of the final version of the manuscript.

\section{Availability of data and materials}

The datasets used and/or analysed during the current study are available from the corresponding author on reasonable request.

\section{Ethics approval and consent to participate}

Not applicable. All the milk samplings were performed during the mastitis monitoring program regularly practiced by the local veterinary practitioner; for this reason, such approval by institutional ethics committee was not necessary. Nevertheless all the clinical actions performed during the study abide by the common good clinical practices [35], moreover the farmer involved was previously informed and in agreement about purposes and methods of the present investigation and a verbal approval have been received.

\section{Consent for publication}

Not applicable.

\section{Competing interests}

The authors declare that they have no competing interests. The authors affiliated with the private company did not influence in anyway the outcomes of the study. They were only involved in conceptual aspect and design of the study and reviewing of the final version of the manuscript. The company that he represents adheres to the Good Publication Practice guidelines for pharmaceutical companies (GPP3) ensuring that the publication is produced in a responsible and ethical manner.

\section{Author details}

'Department of Veterinary Medicine and Animal Production, University of Napoli Federico II, Via Delpino 1, 80137 Naples, Italy. ${ }^{2}$ Istituto Zooprofilattico del Mezzogiorno, Via A. Jervolino 19, Caserta District, 81100 Tuoro, Italy. ${ }^{3}$ Zoetis, Italia s.r.l., Via Andrea Doria 41M, 00192 Rome, Italy. ${ }^{4}$ Veterinary practitioner, Caserta, Italy. 
Received: 13 January 2020 Accepted: 3 June 2020

Published online: 12 June 2020

\section{References}

1. Guccione J, Borriello G, Ciaramella P, Di Loria A. Clinical evaluation of poor milking procedures effects on dairy Mediterranean buffaloes udder health. Large Anim Rev. 2017a;23:155-7.

2. Pisanu S, Cacciotto C, Pagnozzi D, Puggioni GMG, Uzzau S, Ciaramella P, et al. Proteomic changes in the milk of water buffaloes (Bubalus bubalis) with subclinical mastitis due to intramammary infection by Staphylococcus aureus and by non-aureus staphylococci. Sci Rep. 2019;9:15850.

3. Moroni P, Rossi CS, Pisoni G, Bronzo V, Castiglioni B, Boettcher PJ. Relationships between somatic cell count and Intramammary infection in buffaloes. J Dairy Sci. 2006;89:998-1003.

4. Guccione J, Perreten V, Steiner A, Thomann A, Pesce A, Ciaramella P, et al. Short communication: role of Streptococcus pluranimalium in Mediterranean buffaloes (Bubalus bubalis) with different udder health statuses. J Dairy Sci. 2016b;99:2945-9.

5. Guccione J, Pesce A, Pascale M, Salzano C, Tedeschi G, D'Andrea L, et al. Efficacy of a polyvalent mastitis vaccine against Staphylococcus aureus on a dairy Mediterranean buffalo farm: results of two clinical field trials. BMC Vet Res. 2017b;13:29.

6. Guccione J, Cosandey A, Pesce A, Di Loria A, Pascale M, Piantedosi D, et al. Clinical outcomes and molecular genotyping of Staphylococcus aureus isolated from milk samples of dairy primiparous Mediterranean buffaloes (Bubalus bubalis). J Dairy Sci. 2014a;97:7606-13.

7. Zecconi A, Sesana G, Vairani D, Cipolla M, Rizzi N, Zanini L. Somatic cell count as a decision tool for selective dry cow therapy in Italy. Ital J Anim Sci. 2018;18:435-50.

8. Puggioni GMG, Tedde V, Uzzau S, Guccione J, Ciaramella P, Pollera C, et al. Evaluation of a bovine cathelicidin ELISA for detecting mastitis in the dairy buffalo: comparison with milk somatic cell count and bacteriological culture. Res in Vet Sci. 2020;128:129-34.

9. Green M, Huxley J, Madouasse A, Browne W, Medley G, Bradley A, et al. Making good decisions on dry cow management to improve udder health—synthesizing evidence in a Bayesian framework. Cattle Pract. 2008; 16:200-8.

10. Guccione J, Pesce A, Pascale M, Tommasini N, Garofalo F, Di Loria A, et al. Short communication: effects of systemic treatment with penethamate hydriodide on udder health and milk yields in dry primiparous Mediterranean buffaloes (Bubalus bubalis). J Dairy Sci. 2014b;97:2219-25.

11. Biggs A, Barrett D, Bradley A, Green M, Reyher K, Zadoks R. Antibiotic dry cow therapy: where next? Vet Rec. 2016;178:93-4.

12. Bradley A, De Vliegher S, Farre M, Jimenez LM, Peters T, de Leemput ES, et al. Pan-European agreement on dry cow therapy. Vet Rec. 2018;182:637.

13. Cagnardi P, Guccione J, Villa R, D'Andrea L, Di Loria A, Ferrante MC, et al. Clinical efficacy and pharmacokinetics of meloxicam in Mediterranean buffalo calves (Bubalus bubalis). PLoS One. 2017:12:e0187252.

14. DGSA - Direzione Generale della Sanità Animale e del Farmaco Veterinario. Italian Ministry of Health 2009. http://www.trovanorme.salute.gov.it/ normsan-pdf/0000/31298_1.pdf Retrieved 15 March 2019.

15. Scherpenzeel CGM, Santman-Berends IMGA, Lam TJGM. Veterinarians' attitudes toward antimicrobial use and selective dry cow treatment in the Netherlands. J Dairy Sci. 2018;101:6336-45.

16. Scherpenzeel CGM, Tijs SHW, den Uijl IEM, Santman-Berends IMGA, Velthuis AGJ, Lam TJGM. Farmers' attitude toward the introduction of selective dry cow therapy. J Dairy Sci. 2016;99:8259-66.

17. Guccione J, Della Valle G, Carcasole C, Kuhnert P, Alsaaod M. Detection of Treponema pedis associated with digital dermatitis in Mediterranean buffalo (Bubalus bubalis). Vet Rec Case Rep. 2018;6:e000674.

18. Guccione J, Carcasole C, Alsaaod M, D'Andrea L, Di Loria A, De Rosa A, et al. Assessment of foot health and animal welfare: clinical findings in 229 dairy Mediterranean buffaloes (Bubalus bubalis) affected by foot disorders. BMC Vet Res. 2016a;12:107.

19. D'Andrea L, Guccione J, Alsaaod M, Deiss R, Di Loria A, Steiner A, et al. Validation of a pedometer algorithm as a tool for evaluation of locomotor behaviour in dairy Mediterranean buffalo. J Dairy Res. 2017;84:391-4.

20. Guccione J, D'Andrea L, Alsaaod M, Borriello G, Steiner A, Ciaramella P. Validation of a noseband pressure sensor algorithm as a tool for evaluation of feeding behaviour in dairy Mediterranean buffalo (Bubalus Bubalis). J Dairy Res. 2019;86:40-2.
21. Orbenin Extra ${ }^{\oplus}$ label, 2019. Sospensione intramammaria per bovine in asciutta (cloxacillina benzatina). https:/shopdemasit/admin/uploads/ articoli/4599pdf Retrieved 5 March 2019.

22. Lam TJGM, van Wuijckhuise LA, Franken P, Morselt ML, Hartman EG, Schukken YH. Use of composite milk samples for diagnosis of Staphylococcus aureus mastitis in dairy cattle. J Am Vet Med Assoc. 1996;208:1705-8

23. Michel A, Syring C, Steiner A, Graber HU. Intramammary infections with the contagious staphylococcus aureus genotype B in Swiss dairy cows are associated with low prevalence of coagulase-negative staphylococci and streptococcus spp. Vet J. 2011;188:313-7.

24. Whitfield LK, Laven RA. A comparison of the effect of short-acting and long-acting cloxacillin-based dry-cow therapy on somatic cell counts after calving in cows also given internal teat sealants. New Zealand Vet J. 2018;66:44-7.

25. Sol J, Sampimon SJJ, Schukken YH. Factors Associated with Bacteriological Cure After Dry Cow Treatment of Subclinical Staphylococcal Mastitis with Antibiotics. J Dairy Sci. 1994;77:75-9.

26. Bradley A, Barkema H, Biggs A, Green M, Lam T. Control of Mastitis and Enhancement of Milk Quality. In: Green M, editor. Dairy herd health. Oxford: CABI International; 2012. Chapter 5. p. 117-68 1.

27. Reeve-Johnson L, Nickerson SC. A large multi-centric study in the United States assessing self-cure rates in dairy cows during the dry period from mastitis due to Staphylococcus aureus. Anim Husb, Dairy Vet Sci. 2017;1:1-7.

28. Linage B, Gonzalo C. Influence of an intramammary infusion at drying-off of combined penethamate hydriodide, benethamine penicillin, and framycetin sulfate on intramammary infections and somatic cell counts in dairy sheep. J Dairy Sci. 2008;91:3459-66.

29. Dingwell RT, Duffield TF, Leslie KE, Keefe GP, DesCoteaux L, Kelton DF, Lissemore KD, Schukken YH, Dick P, Bagg R. The efficacy of intramammary tilmicosin at drying off, and other risk factors for the prevention of new intramammary infections during the dry period. J Dairy Sci. 2002;85:3250-9.

30. Rajala-Schultz P, Persson Waller K, Halasa T, Nødtvedt A. Selective approach to dry cow therapy. Vet Rec. 2019;184:29-30.

31. Trinidad P, Nickerson SC, Adkinson RW. Histopathology of staphylococcal mastitis in unbred dairy heifers. J Dairy Sci. 1990;73:639-47.

32. Enger BD, Crutchfield CE, Yohe TT, Enger KM, Nickerson SC, Parsons CLM, Akers RM. Staphylococcus aureus intramammary challenge in non lactating mammary glands stimulated to rapidly grow and develop with estradiol and progesterone. Vet Res. 2018;49:47.

33. Skidmore AL, Peeters KAM, Sniffen CJ, Brand A. Monitoring dry period management. In Brand a, Noordhuizen JPTM and Schukken YH, editors. Herd health and production Management in Dairy Practice. 2001. Capter. 2001:3:171-201.

34. National Mastitis Council. Procedures for Collecting Milk Samples in Microbiological Procedures for the Diagnosis of Bovine Udder Infection and Determination of Milk Quality. Madison: National Mastitis Council Inc; 2004.

35. EMA, 2000. VICH GL9: Guideline on Good Clinical Practice. EMA/CVMP/VICH/ 463202/2009

36. National Mastitis Council Diagnostic procedures in Laboratory Handbook on Bovine Mastitis, 3rd Edition. New Prague: National Mastitis Council Inc. 2017

37. Petrie A, Watson P. Experimental design and clinical trials. In: Petrie A, Watson P, editors. Statistics for Veterinary and Animal Science. 3rd ed. Oxford: Wiley; 2013. Capter 5. p. 55-74.

\section{Publisher's Note}

Springer Nature remains neutral with regard to jurisdictional claims in published maps and institutional affiliations. 